\title{
Digital Transformation at Universities: Global Trends and Vietnam's Chances
}

\author{
Phung The VINH* \\ School of Business Administration, VNU University of Economics and Business, Hanoi \\ *Corresponding author: vinhpt99@gmail.com
}

\begin{abstract}
Research purpose:

The study aims at investigating the meanings and impacts of digital transformation on universities from global perpectives and also looking at how Vietnam's universities can seize the opportunities and overcome the challenges from digital transformation.
\end{abstract}

\section{Research motivation:}

Digital transformation is simply understood as the process whereby changes are made, so that digital developments are replacing conventional methods in order to achieve faster production and better performance. As a result, the implementation of digital transformation will have a substantial impact on our life. As universities have a mission to educate, digital transformation help them improve the mission. However, it also brings about a lot of challenges for universities. Vietnam is still in the developing stage; as such, its universities must identify and take advantage of digital transformation while avoiding its negative impacts.

\section{Research design, approach and method:}

The study uses a qualitative method to explore, analyze and assess all facets of digital transformation. Case-studies, depth-interviews, and surveys are conducted to find out the opinions toward the process of digital transformation in Vietnam's universities. Secondary data is collected from state statistics, research papers, and universities' published documents.

\section{Main findings:}

The digital transformation is strongly going on in universities all over the world, which is putting a pressure on Vietnam's universities to change and adapt to new circumstances. While there are some disadvantages associated with digital transformation, the advantages might still outweigh the disadvantages. For example, enhancing education qualitative, making teaching and studying processes more flexible. Besides, applying digital transformation in university administration helps them manage and control daily work efficiently.

\section{Practical/managerial implications:}

The result of the research has delivered a comprehensive overview of digital transformation while providing important lessons for universities. This recommendation is to find out that (1) the universities have to construct key strategies regarding digital transformation; (2) the university leaders should adopt new perspectives and management strategies towards digital transformation; (3) every lecturers, students and staffs should be equipped with modern technological skills; (4) the culture of strong digital leader needs to be built in every universities; (5) the legal framework system needs to be built methodically to ensure the curriculum's outputs quality.

Keywords: digitalization, digital transformation, university, e-learning, online teaching.

\section{INTRODUCTION}

In recent years, digital transformation is no longer a new concept to scholars in the world and Vietnam. Digital transformation has a far-reaching impact, covering all industries and socio-economic level, and directly affecting enterprises' business performance, such as improving productivity, profits and cost reduction. It also affects the long-term performance indicators of enterprises, contributing to improving the country's competitiveness (Microsoft, 2018).

Digital transformation is considered the current inevitable trend for enterprises, organizations, and the state. This trend forces businesses, organizations, and governments to revolutionize their approach to operations, product and service delivery, marketing efforts, and every other aspect of their organizations. In the context of globalization of higher education, universities enter the global competition. (Gafurov et 
al., 2014; 2017). Under such conditions, the universities' competitiveness will be determined by The timely introduction of new technology, the degree of significant types of digitization activities (Maltese, 2018; Kryukov et al., 2017).

Digital transformation in organizations and businesses are changing from a traditional model to a digital enterprise by applying new technologies such as big data (Big Data), Internet of Things (IoT), and Cloud computing-(Cloud), and changing operating methods, leadership, working processes, and company culture. Digital transformation offers various benefits such as cutting operating costs, expanding the customer base, leading to faster and more accurate decision-making. Therefore, organizations' and enterprises' operational efficiency and competitiveness are improved (Petkovics, 2018). Universities are institutions that research and provide educational services, spreading and developing human knowledge. Therefore, without digital transformation and successful digital transformation, universities may fail to be a place that attracts, trains, and leads scientists, students, and businesses (Phung, 2020). How is digital transformation in Vietnamese universities happening? What are the successes and shortcomings in the digital transformation of universities? This study will partly clarify these issues.

\section{LITERATURE REVIEW}

There are several different definitions of "digital transformation", depending on the context of use in today's world. According to the study, Maltaverne (2017) introduced three words "digitization", "digitalization", and "digital transformation". These terms are often used interchangeably. The fact that many people consider these words interchangeable shows the confusion about what digital transformation requires. The first phase is described as to Maltaverne (2017), "Digitization" refers to "the conversion from analog to digital" (e.g., digitization of data). Garnter used the term "digitization" to emphasize that "the goal is to create and deliver new value to customers, not just to improve what is already being done or offered" (Moore, 2015).

Meanwhile, OED (2016) defined the term "digitization" to be "the adoption of or increase in the use of digital or computer technology by an organization, industry, country, etc." According to Schallmo, A., \& Daniel, R (2018), digitization is defined as the digital enabling of analog or physical artifacts to implement said artifacts into business processes with the ultimate aim of acquiring newly formed knowledge and creating new value for stakeholders. In addition, several authors share similar definitions (Feldman, 1997; Pepperell, 2003; Pinch and Trocco, 2004; Robinson, 2008).

The second phrase is "digitalization - the process of using digital technology and its impacts" (e.g., digitalization of a process). Unruh \& Kiron (2017) had similar interpretations and described digitalization as "the innovation of business models and processes that exploit digital opportunities." A digital business consulting firm, I-SCOOP (2016), offered a brief definition of digitalization. "Digitalization means the use of digital technology and data (digitized and natively digital) to generate revenue, improve business operations, replace/transform business processes (not simply digitizing them), and create an environment for digital business where digital information is at the core." These digitalization terms indicate different nuances of meaning, depending on the kind of organization. The definitions need to be clearly distinguished to avoid confusion that can change the power and importance of digital transformation, which might put their organization in jeopardy. (Bloomberg, 2018), Unruh \& Kiron (2017) defined the terms to create a framework that helps managers and policymakers think about the use of digital technology to address the world's sustainability issues. Some cases describe the social implications of increased computer assistance, new media, and communication platforms for the economy, society, and culture (Castells, 2010; Dijk van, 2006; Verhulst, 2002; Sassen and Appiah, 1998).

Finally, "digital transformation" is the most inclusive of the three terms that cover the whole enterprise, not just a specific process. Schallmo \& Daniel (2018) pointed out that digital transformation is defined as fundamental changes made to business operations and business models based on new knowledge through value-added knowledge. Bloomberg (2018) and Peter (2017) have the same opinion that digital transformation is oriented by the customers, which requires organizational change across the board with the implementation of digital technologies. The use of traditional technologies such as Enterprise Resource Planning (ERP) transforms customer relationships, internal processes, and value propositions (Westerman et al., 2011). Meanwhile, Daim (2020); Daniotti et al. (2020) suggested that digital transformation simply refers to the change processes whereby the change is made so that digital and digital developments are replacing conventional methods of achieving digital transformation faster and better performance. Maltaverne (2017) describes that it leads to creating entirely new markets, customers, and businesses. According to Unruh \& Kiron (2017), digital transformation occurs when new digital business models and processes restructure economies. Societies also evolve as people integrate technologies into their lives and habits. The three terms/concepts are summarised and visualized in figure 1 . 


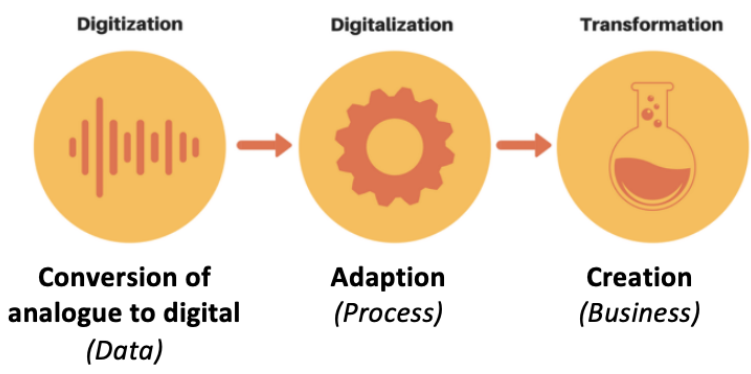

Fig. 1: Definition of Digitisation, Digitalisation and Digital Transformation (Maltaverne, 2017)

In the context of digital transformation, managers must adjust their business strategies to be able to adapt and manage their operational processes well (Reis et al., 2018). Building an organization's digital transformation strategy is crucial as the central concept for integrating the entire orchestration, prioritization, and execution of digital transformation within a company (Matt et al., 2015). Higher education across the world faces the same reality. The digitalization initiative is deeply influenced by public policy and institutional development strategies, both of which play a crucial role in shaping the digitalization landscape of higher education ( Walker, Voce, \& Jenkins, 2016). Digitalization is framed as an inevitable choice for developing education in an intelligent environment. Artificial intelligence, big data, blockchain, and other emerging technologies will change the way teaching and learning occur and lead to the reconceptualization of education and its culture and ecology (Xiao, 2019). The main directions of global digital transformation are integrated into the university's activities and strategies. Shared knowledge resources become a reliable basis for decision making throughout the life cycle of infrastructures. The changes in the system and infrastructure of educational organizations are inevitable. Research by Branco et al. (2015) considered it important to conceptualize the creation of a decision support system for the university's IT infrastructure. The university has to meet new requirements. The university's flexibility and adaptability in the new digital era should fundamentally increase (Gafurov et al., 2020). Digital transformation is a slow process in education that has become an urgent topic due to the COVID-19 pandemic. Bogdandy et al. (2020) surveyed the Computer Science and Information Technologist students of the Eszterhazy Karoly University (Hungary); based on the results, the students enjoyed the digital education, and half of them were willing to continue it in the future. In several universities, using e-learning or a learning management system (LMS) is a solution to promote digital transformation. E-learning allows more students to access higher education (Aldiab et al., 2017), but the application also challenges higher education institutions. LMS platform selection should be based on the actual needs of the users to most conveniently meet their needs (Kasim and Khalid, 2016).

Besides the factors such as strategies and infrastructure, increasing and retaining human capital is key for the performance of universities (Gander et al., 2019). The digital transformation poses new challenges for universities. The challenges that Trento university have faced are organizational, technical, legal and security, and user-related challenges (Maltese, 2018). Researching on digital transformation in education in Germany, Bond (2018) believed that in order to promote successful digital transformation in universities, the university administration must simultaneously implement top-down and bottom-up management methods. Firstly, it is necessary to understand teachers' and students' technical literacy to provide support if any gap in computer skills is identified. Secondly, it is required to have the support and promotion of the university administration to form an overall digital transformation environment in the university. The lack of digital knowledge and skills also hinders the use of technology in the classroom and some other problems; young teachers, who are new to the profession, are believed to be able to adapt to rapid change and development rather than experienced teachers (Englund et al., 2017).

In summary, the digitization process consists of three stages, and each stage contains a different meaning:

\section{- Digitization is the move from analogue to digital}

- Digitalization is using digital data to simplify how you work

- Digital transformation is a comprehensive change of business models and organizations with digital information

Digital transformation in higher education is understood as digital transformation in educational administration and teaching, learning, testing, and assessment, etc.

Educational administration includes digitalization management information, creating a sizeable interconnected database system and applying technology 4.0 (AI, blockchain, data analysis, etc.) to manage, operate, forecast, and support decision-making in education quickly and accurately. Teaching, learning, testing, and evaluating involve digitized documents (e-textbooks, electronic lectures, e-learning lecture repositories, multiple choice question banks etc.), digital libraries, virtual laboratories, implementing online training systems, and building virtual universities.

\section{METHODOLOGY}

\section{Research sample}

To find out the current situation of digital transformation among universities in Vietnam, several typical universities from three regions (North, Central, and South) are selected as main case studies to be analysed. Particularly, these universities should include both public and private universities to ensure data validity and reliability. The survey includes five 
universities. In this research, the information of universities is confidential. Therefore, the author used pseudonyms such as A, B, C, D, and E to describe, and sometimes the description of particular incidents may be vague to avoid identification. Research was conducted via an online form. The author called a total of 60 people including different audiences to ask about their behaviors, perceptions and opinions about the current digital transformation situation. The main respondents were Vice-Rector, manager, lecturers and staffs from universities. They are the people who are directly involved in and affected by the digital transformation process in their work. For example, the Vice-Rector uses data analytics technology to devise appropriate development strategies. Managers perform the tasks assigned by the principal and control staffs (integrating technology into assigned work by task management software) and lecturers applying technology in teaching, testing, evaluation ... Therefore, their answers bring great practical significance to the research. The number of interviewees is summarized as below:

Table 1: Summary of interviews and case sites

\begin{tabular}{|c|c|c|c|c|c|}
\hline & $\begin{array}{c}\text { Vice } \\
\text {-Rector }\end{array}$ & Manager & Lecturers & Staffs & Total \\
\hline A & 02 & 03 & 03 & 04 & $\mathbf{1 2}$ \\
\hline B & 01 & 04 & 04 & 03 & $\mathbf{1 2}$ \\
\hline C & 01 & 03 & 03 & 04 & $\mathbf{1 1}$ \\
\hline D & 01 & 05 & 04 & 03 & $\mathbf{1 3}$ \\
\hline E & 01 & 04 & 03 & 04 & $\mathbf{1 2}$ \\
\hline \multicolumn{7}{|c|}{ Total interviews } \\
\hline
\end{tabular}

Out of 60 interviewees, 23 were female, and 37 were male. The candidates all have worked at the university for five years or more, and the ages range from 35 to 55 . Especially in the total number of candidates, there is one professor, seventeen doctors, and master's level is the others. That is shown in the table below:

Table 2: Summary of information on qualifications, gender, and age of interviewees

\begin{tabular}{|c|c|c|c|c|}
\hline & Professor & Doctor & Master & Total \\
\hline M & 01 & 09 & 27 & $\mathbf{3 7}$ \\
\hline F & 0 & 08 & 15 & $\mathbf{2 3}$ \\
\hline Ages & \multicolumn{3}{|c|}{ From 35 to 55 } & $\mathbf{6 0}$ \\
\hline
\end{tabular}

Research method

In this study, the qualitative method is carried out to achieve research objectives. The method with an in-depth interview is widely used and recommended to study phenomena in rich contexts where there are always many variables to consider compared to the number of observations made. This method can be utilized to collect, synthesize, and analyze information from respondent's opinions and behaviours towards a specific topic. Three interview questions that five universities have to answer are: (1) What opportunities and challenges does digital transformation bring to your university?, (2) How is digital transformation in your university?, and (3) What should your university do to encourage digital transformation?. Besides, two important keywords that should be used to find secondary studies are "university" and "digital transformation". After exploring the practical situation and explaining how the digital transformation process occurs in several universities through prior researches and in-depth interviews, several findings for the context of Vietnam can be proposed.

\section{Data synthesis}

Firstly, researcher look at the context in which the content and goal of digital transformation process at universities can be perceived from the data, then extracted and codified. Moreover, researcher analyses interview data to identify concepts and develop categories about opportunities and challenges of digital transformation, which are emerged from interview content. Importantly, this should be conducted basing on key principles for digital transformation after generalizing and incorporating them into an overall background. As such, the information synthesis process can make objective assessments and comments as a basis for proposing solutions to promote the digital transformation process at universities. These findings will contribute a better overview of the current digital transformation landscape amongst Vietnamese universities and suggest the promotion of the digital transformation process for better results.

\section{RESULTS AND DISCUSSION}

Vietnam's context

In recent years, there are many young people using smartphones and the internet in Vietnam. Therefore, young people are getting used to a digital environment. This is a head start for promoting digital transformation in higher education. According to statistics, the number of internet users in 2021 reach 68.72 million, accounting for $70.3 \%$ of the population. Vietnam can be in the top 10 countries with the highest percentage of people accessing the Internet, with about $80 \%$ of the people using the Internet by 2020. Particularly in the social network segment, as of January 2021, there are 72 million users, accounting for $73.7 \%$ of the population (Kemp, 2021). The high percentage of Internet users in the population is one of the initial conditions to help Vietnam access education 4.0 faster. On June 3, 2020, the Government decided to approve the "National digital transformation program to 2025 , orientation to 2030". Orientated from 2025-2030, education and training are one of the top 8 priority areas in digital transformation.

The Covid-19 pandemic has also been expediting a digital transformation in Vietnam. Since March 2020, Vietnam's government has repeatedly highlighted the vital role of technology and digital transformation in education. So that universities have to transform their 
activities into digital ways. In a bid to become a world-class university in Vietnam, Vin University realized the desire need for the digital transformation of its campuses. Its leaders sought to improve the overall academic experiences by implementing industry-leading digital solutions for both educational and administrative requirements. For instance, medical students are benefiting immensely from a new medical training technology. This technology creates a virtual environment in which to practice clinical techniques.

Similarly, the university is improving student engagement and outcomes through enterprise-level CRM (Customer Relationship Management) solutions by obtaining insights into campus data (Raj Mruthyunjayappa, 2021). As a result, The Ministry of Education and Training (MOET) is amending some regulations on full-time university education, allowing universities to carry out online training hours at a certain level. It becomes essential for higher education institutions to identify goals, needs, and capabilities clearly, thereby actively cooperating with businesses and investing appropriately for more effective online training in Vietnam.

\section{The opportunities of digital transformation}

The interview recognizes the opportunities that digital transformation brings universities, students, and society. According to the interviewees, especially leaders (vice-rectors), the first opportunity is improving the quality of education. The survey of university A shows that applying technologies such as IoT (Internet Of Things) enhances classroom management and monitors students' behavior effectively, thereby helping to analyze students' learning behavior for appropriate support and feedback. Candidates B, C, D, and E believe that building an information management system and learners' educational records is also a perk of digital transformation. Information and data about the student's schedule, learning history, and transcripts are uniform and transparent. Most universities have open learning resources to help learners and lecturers connect with knowledge effectively. In Vietnam, distance-learning or e-learning was used in universities and colleges in the early years of the 21 st century. However, top-rank Vietnam's universities were reluctant to apply e-learning for their official full-time program because the quality of this teaching method was uncertain. As digital transformation accelerated, Vietnam has joined Asia E-learning Network - AEN, (www.asia-elearning.net) with the participation of the Ministry of Education and Training (MOET), Ministry of Science and Technology, Hanoi University of Science \& Technology, Ministry of Information and Communications, ICT department. MOET has systematically launched e-learning to provide e-learning information in the world and Vietnam. (Tien and Tang, 2020).

Second, an open mass online course (MOOC) can create a flexible learning time and promote accessible education. All universities agreed that students can access multi-dimensional information, narrow all spaces, and optimize time, thereby developing quickly in knowledge, perception, and thinking. University E has applied virtual reality technology VR (Virtual Reality), AR (Augmented Reality) in teaching, simulating experiments to help students develop a multi-sensory experience that is easy to understand and remember. The remaining universities applied online teaching tools such as LMS, E-learning lectures, and some advanced teaching methods such as applying educational trends in intelligent classroom technology, gamification, programming, multiple-choice question banks, etc., in teaching. Lecturers and staffs have most enthusiasm on this DT's benefit.

Finally, technology is applied to management and administration. According to the survey, applying technology to operations helps to manage lecturers and students more effectively. The university can cut costs and increase the efficiency and working quality of the office and training blocks. Online teaching models (e-learning) also help reduce training and course costs. In June 2020, the Prime Minister approved the National Digital Transformation Program to 2025, with orientation to 2030, in which education and training are one of the top priority areas in implementation. The goal for Vietnam is to become one of the leading countries in digital transformation in education and training as well as universities. Therefore, interviewees as manager highly evaluate the role of DT in university administration.

\section{The challenges of digital transformation}

The first challenge to mention is the technology application capacity of universities. The survey shows that some universities applied technology to online teaching many years ago. However, there are still universities that are not familiar with this form of training, and the facilities and information infrastructure are not yet familiar to ensure to conduct online teaching effectively and promote learners' capacity. Candidates for $\mathrm{B}$ and $\mathrm{C}$ believe that facilities, network infrastructure, equipment (such as computers, cameras, printers, scanners), transmission lines, Internet services are lacking and lose backward, not synchronized with requirements for digital transformation. It can be seen that this is also the common situation of some universities in Vietnam. At the same time, A, C, and E have invested in facilities to meet teaching quality assurance Online and executive management requirements. The interview survey results with A show that all the universities's activities have been digitized in the two years 2019-2021. The school has strengthened the organization of online teaching and is perfecting this teaching process.

The second challenge that the candidates share is about digitizing specialized databases such as learner data, teacher/lecturer data, learning materials, etc., which requires a significant investment in human resources. 
(including management and implementation personnel) as well as finance to ensure digitization. According to the survey of A and E, building such a data system could allow universities to use these tools to analyze the performance of faculty, students, and staffs. These implementations can support decision-making and improve teaching efficiency, student recruitment rate, thereby creating competitive advantages. B, C, and D also have the same opinion; however, B believes that building a digital data warehouse (such as e-books, electronic libraries, multiple-choice question banks, essays, etc.) e-learning, e-learning software, simulation application software) is also an important topic to pay attention to and universities need to have specific, synchronous plans to avoid spontaneous development leading to waste of time, effort, and money.

The third challenge identified by candidates concerns the quality of online learning programs. The significant challenges for the surveyed universities are the development of online learning programs, the structure of study time, online assessment tests, and the recognition of online learning results (different from traditional learning). Government regulations and guidelines for this form of online learning are still not specified. A, C and $\mathrm{E}$ have only begun to establish regulations on conditions for organizing classes in the network environment (short-term and long-term), while $\mathrm{B}$ and $\mathrm{D}$ are also in the stage of developing implementation plans.

The final challenge identified by the surveyed universities is related to financing. According to A, a considerable investment is devoted to digital transformation in teaching, conversion, and investment in digital equipment systems. For example, hardware, software, technology devices, smart classrooms come with imaginative pedagogical activities, learner management, intelligent lecturers, and an intelligent curriculum. $\mathrm{C}$ and $\mathrm{E}$ believe that universities need to plan specific monetary funds to avoid budget shortages that affect the university's brand and competitive advantage.

\section{RECOMMENDATION AND CONCLUSION}

From all description above, the author proposes several solutions for successful digital transformation in universities as encapsulated below.

Firstly, for leaders and managers, universities need to identify fine a key strategy in the coming period, focusing on improving the infrastructure. New technology and equipment infrastructure is the foundation on which all educational and management activities of all levels take place. The teaching and management software systems shall be compatible and interconnected in the same ecosystem and comply with information security.

Secondly, the thinking and management capacity of universities leaders must change, as viewpoints of lecturers and staffs. It is necessary to be sensitive to grasp and take advantage of the digital transformation process's opportunities. Cultivate and equip digital knowledge and thinking to be able to master technology and understand its limits.

Thirdly, technological skills need to be enhanced with training. Students, lecturers, and administrators need to hone their skills in using technology. Sustained effectiveness is when both learners and lecturers are well trained to use digital media to achieve educational goals. In addition, the accompanying support of technical staffs and technology experts needs to be enhanced to ensure smooth and fluent teaching. However, lecturers and staffs must spend more time and effort, as their inertia are bigger than other groups.

Fourthly, the cultural foundation of skills education needs to be built. Building a culture of freedom of experience allows students to discover new fields and gain experience. Students need to be educated, develop new skills, and enhance readiness, initiative, and attitude to learning.

Fifthly, the legal framework system needs to be built methodically to ensure the quality of the outputs of the curriculum. Education quality accreditation can be strengthened by external assessment organizations to recognize educational content and programs that meet international educational quality standards.

Digital transformation taking place at universities is an inevitable and global trend. Initial successes are the foundation for further success. The digital transformation process itself is a challenge in the application of technology solutions and requires people and organizations to change their way of thinking. Therefore, it is not enough for the university organization to optimize internal administrative processes using technology. It is essential that its leadership clearly understands why it needs to do this, what its capabilities and goals are, and the long-term consequences for its operational capacity and expansion plans. Digital transformation contains challenges and opportunities, and provides the tools and methods to turn this challenge into an opportunity.

\section{ACKNOWLEDGMENTS}

Digital transformation in universities has inspired and motivated the author to conduct research. The author's achievements would not have been possible without the support of the universities and the author's colleagues. Importantly, my personal appreciation for individual interviewees and universities should come first. Moreover, special thanks to Assoc. Prof. Nguyen Anh Tuan and Ph.D Nguyen Ngoc Quy for supporting this article. 


\section{REFERENCES}

[1] Aldiab, A., Chowdhury, H., Kootsookos, A., \& Alam, F. (2017). Prospect of eLearning in higher education sectors of Saudi Arabia: A review. Energy Procedia, 110, 574-580.

[2] Bloomberg, J. (2018). Digitization, digitalization, and digital transformation: confuse them at your peril. Forbes. Retrieved on August, 28, 2019.

[3] Bogdandy, B., Tamas, J., \& Toth, Z. (2020). Digital transformation in education during covid-19: A case study. In 2020 11th IEEE International Conference on Cognitive Infocommunications (CogInfoCom) (pp. 000173-000178). IEEE.

[4] Bond, M., Marín, V. I., Dolch, C., Bedenlier, S., \& Zawacki-Richter, O. (2018). Digital transformation in German higher education: student and teacher perceptions and usage of digital media. International Journal of Educational Technology in Higher Education, 15(1), 1-20.

[5] Branco, F., Martins, J., Gonçalves, R., Bessa, J., \& Costa, A. (2015, June). A decision support platform for IT infrastructure management: The university of Trás-os-Montes e Alto Douro services of information and communications case study. In 2015 10th Iberian Conference on Information Systems and Technologies (CISTI) (pp. 1-7). IEEE.

[6] Castells, M. (2010). The rise of the network society, 2nd ed., With a new pref. Chichester, West Sussex ; Malden, MA: Wiley-Blackwell.

[7] Daim, T. U. (Ed.). (2020). Digital Transformation: Evaluating Emerging Technologies (Vol. 6). World Scientific.

[8] Daniotti, B., Gianinetto, M., \& Della Torre, S. (202 $0)$. Digital transformation of the design, constructi on and management processes of the built environ ment (p. 400). Springer Nature.

[9] Dijk van, J. (2006). The network society: social aspects of new media, 2nd ed. Thousand Oaks, CA Sage Publications.

[10] drivers for change in UK higher education. Show Me The Learning. Proceedings ASCILITE, 2016, 278-282.

[11] Englund, C., Olofsson, A. D., \& Price, L. (2017). Teaching with technology in higher education: Understanding conceptual change and development in practice. Higher Education Research and Development, 36(1), 73-87.

[12] Feldman, T. (1997). An introduction to digital media. London; New York: Routledge.

[13] Gafurov, I. R., Safiullin, M. R., Akhmetshin, E. M., Gapsalamov, A. R., \& Vasilev, V. L. (2020). Change of the Higher Education Paradigm in the Context of Digital Transformation: From Resource
Management to Access Control. International Journal of Higher Education, 9(3), 71-85.

[14] Gafurov, I. R., Safiullin, N. Z., Safiullin, L. N. \& Odintsova, J. L. (2014). Education system of the world: Modern trends. Mediterranean Journal of Social Sciences, 5(18 SPEC. ISSUE), 91-94.

[15] Gafurov, I., Safiullin, M. \& Elshin, L. (2017). Mechanisms of higher school development in the paradigm of its global competitiveness (on the example of the Kazan Federal University). Revista QUID (Special Issue), 1495-1500.

[16] Gander, M., Girardi, A. and Paull, M. (2019), "The careers of university professional staff: a systematic literature review", Career Development International, Vol. 24 No. 7, pp. 597-618.

[17] Kasim, N. N. M., \& Khalid, F. (2016). Choosing the right learning management system (LMS) for the higher education institution context: A systematic review. International Journal of Emerging Technologies in Learning, 11(6).

[18] Kemp S. (2021). Digital .(2021:) VIETNAM. [online] Available at https://datareportal.com/reports/digital-2020-philippines [Accessed 20 Aug 2021].

[19] Kryukov, V. \& Gorin, A. (2017). Digital technologies as education innovation at universities. Australian Educational Computing, 32(1).

[20] Maltaverne, B. (2017). Digital transformation of Procurement: a good abuse of language?. [online] Available https://medium.com/procurement-tidbits/digital-tra nsformation-of-procurement-a-good-language-abu se-bfcf565b957c [Accessed 20 Aug 2021].

[21] Maltese, V. (2018). Digital transformation challenges for universities: Ensuring information consistency across digital services. Cataloging \& Classification Quarterly, 56(7), 592-606.

[22] Matt, C., Hess, T., \& Benlian, A. (2015). Digital transformation strategies. Business \& information systems engineering, 57(5), 339-343.

[23] Microsoft. (2018). Unlocking the Economic impact of Digital Transformation in Asia Pacific. [online] Available at https://news.microsoft.com/uploads/2018/03/Digit al-Transformation-study-March-2018.pdf [Accessed 20 Aug 2021].

[24] Moore, S. (2015). Digitalization or automation is there a difference? [online] Available at http://www.gartner.com/ smarterwithgartner/digitalization-or-automation-isthere-a-difference/ [Accessed 20 Aug 2021].

[25] OECD (2015a). Schooling redesigned. OECD Publishing. 
[26] OED Online, "digitization, n," Oxford University Press, Sep. 2016

[27] Pepperell, R. (2003). The posthuman condition: consciousness beyond the brain, New ed. Bristol, UK ; Portland, OR: Intellect.

[28] Peter, M. K. (Ed.). (2017). KMU-Transformation: Als KMU die Digitale Transformation erfolgreich umsetzen.: Forschungsresultate und Praxisleitfaden. BoD-Books on Demand.

[29] Petkovics, I. (2018). Digital transformation in higher education. Journal of Applied Technical and Educational Sciences, 8(4), 77-89.

[30] Phùng, T. V. (2020). Quản trị đại học theo tinh thần doanh nghiẹp: Nghiên cưu điển hình mọt số truòng đại học khối ngành kinh tế-kinh doanh trên dịa bàn Hà Nội (Doctoral dissertation).

[31] Pinch, T.J and Trocco, F. (2004). Analog days: the invention and impact of the Moog synthesizer, New ed. Cambridge, Mass.: Harvard University Press.

[32] Raj Mruthyunjayappa. (2021). The Impact of Digitalization for Higher Education in Vietnam. Digital Transformation (Dx).

[33] Reis, J., Amorim, M., Melão, N., \& Matos, P. (2018, March). Digital transformation: a literature review and guidelines for future research. In World conference on information systems and technologies (pp. 411-421). Springer, Cham.

[34] Robinson, D. (2008). "“Analog.," in Software Studies: A Lexicon, edited by Matthew Fuller, Cambridge: MIT Press, pp. 21-31.

[35] Sassen, S and Appiah, K.A. (1998). Globalization and its discontents: [essays on the new mobility of people and money]. New York, NY: The New Press.

[36] Schallmo, A., \& Daniel, R. (2018). Digital Transformation Now! Guiding the Successful Digitalization of YourBusiness Model. Springer Science+ Business Media, LLC.

[37] SCOOP. (2016). Digitization, digitalization and digital transformation: the differences. [online] Available https://www.i-scoop.eu/digital-transformation/digit ization-digitalization-digital-transformation-disrup tion/ [Accessed 20 Aug 2021].

[38] Tang, S. M., \& Tien, H. N. (2020). Digital Transformation Trend in Vietnam Higher Education: Blended Learning Model. International Journal of Social Science and Economics Invention, 6(07), 304-309.

[39] Unruh, G. \& Kiron, D. (2017). Digital Transformation On Purpose. [online] Available at https://sloanreview.mit.edu/article/digital-transfor mation-on-purpose/ [Accessed 20 Aug 2021].
[40] Verhulst, S. (2002). "About Scarcities and Intermediaries: the Regulatory Paradigm Shift of Digital Content Reviewed," in L. A. Lievrouw \& $S$. Livingstone (Eds.), The Handbook of New Media, London: Sage Publications, pp. 432-477.

[41] Walker ,R., Voce, J., Jenkins, M., Ahmed, J., Swift, E., \& Vincent, P. (2016). Refocusing institutional TEL provision on the learner:

[42] Westerman, G, C Calméjane, D Bonnet, P Ferraris and A McAfee. (2011). Digital trans- formation: A roadmap for billion-dollar organizations. MIT Center for Digital Business and Capgemini Consulting, 1-68

[43] Xiao, J. (2019). Digital transformation in higher education: critiquing the five-year development plans (2016-2020) of 75 Chinese universities. Distance Education, 40(4), 515-533. 